\title{
Research on Path Planning Optimization of Body Welding Robot
}

\author{
Qiu Zhimin, Ye Lan \\ Jiangxi Engineering Laboratory of Digital Manufacturing for Automobile Parts, Nanchang institute of \\ science and technology, Nanchang 330108, P. R. China
}

Keywords: body welding, robot, path planning, optimization problem

\begin{abstract}
The body welding work is relatively large; the use of body welding robots greatly reduces the workload of workers, and enhances the work efficiency of body welding. Body welding robots instead of workers to weld the body can also reduce the cost, and body welding robots are more intelligent, conforming to requirements. Therefore, it is necessary to study the path planning of body welding robots. The optimization of path planning of body welding has always been a concern in automobile manufacturing. This paper mainly makes some analysis and researches on the path optimization of body welding robots planning and puts forward some views and contacts.
\end{abstract}

\section{Introduction}

With the continuous development and progress of society, cars are playing a very important role both in transportation and daily use. It can be seen from this that car production now appears to be a very promising market. Robot welding technology has become popular at home and abroad, the current automotive manufacturing industry have adopted a robot welding technology. This technology can effectively improve the bodywork welding efficiency, increase production, and shorten the production time. In short, robot welding technology plays a decisive role in the manufacturing of automobiles.

\section{Problems in current path planning of welding robot body}

Body welding robot can effectively improve work efficiency, so that the body welding work rose to a new level. However, there are some problems in the current body welding robots at work, among which the problems in path planning of body welding robots are the most prominent. In the current path planning, path planning is generally done manually. This artificial path planning algorithm is not reasonable, and the computational efficiency is quite low. In the process of manual path planning, some formula calculation and so on relies entirely on artificial calculation reasoning, this method greatly reduces the work efficiency. And the accuracy of manual estimation is not high, which leads to the unreasonable path planning. In the whole process of body welding robots, the path planning is the core of the whole work process. Only when the path planning is smooth and reasonable, can the body welding robots work normally. However, the current path planning unreasonable caused the body welding robot program unreasonable, all kinds of planning paths messy, there is no law. Such path planning poses a serious obstacle to the work of the body welding robot and also has a serious impact on the welding work of the automobile body. Want to fundamentally solve the problem of body welding robot work, but also need to start from the path planning. First of all, we must understand the characteristics of body welding work and the characteristics of the path planning, and then based on its characteristics to develop a detailed path planning program.

\section{Body welding robot main workflow}

First of all, it is transport; the welding robot will be required to transport the welding of body materials in place. The second step is to locate and fix the body, this step of the operation is mainly to find the location and fixed, in order to carry on the next job. The third step is the formal welding 
work, the body of the overall welding. The last step is to loosen the fixture and remove it. The main work flow of the welding robot is the main welding operation, the welding robot body can automatically carry out welding work and the next car body welding, the process is done by the body welding robot. This process embodies the intelligence and work efficiency of the body welding robot, which is a major feature of the body welding robot work.

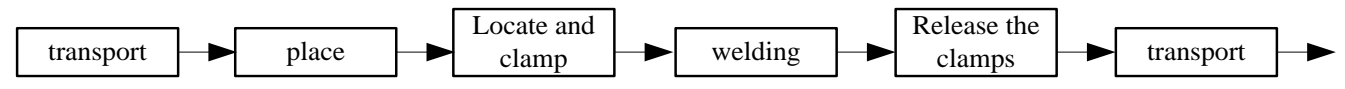

Figure 1. White body welding process

\section{Optimize the path planning of body welding robot}

Body welding robots in the welding operation, mainly in an automatic way to body welding work. A car body welding requires a lot of points of welding, welding of these points are done by the body robot initiative. In the body welding work, the robot follows the welding law is completely determined by the path planning.

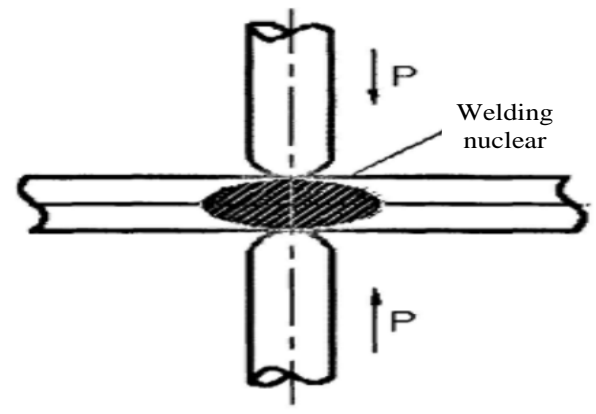

Figure 2. Spot welding schematic

In the bodywork robot welding work, all parts of the body need to be welded, then you want to improve work efficiency, so that bodywork welding robots can work faster and improve work efficiency.

The source of spot welding is the resistance heat generated by the current through the weld zone. According to Joule's law, the total fever W is:

$$
W=\int_{0}^{T} \dot{i}^{2}(t) R(t) d t
$$

Where $\mathrm{i}(\mathrm{t})$ is the instantaneous current through the weld zone, A; R (t) is the resistance of the weld zone; $\mathrm{T}$ is the current through the weld; where the resistance $\mathrm{R}(\mathrm{t})$ is the total resistance at spot welding.

Welding makes resistance is an internal heat source is an important factor in the formation of the welding temperature field is an inherent factor. Welding resistance can be divided into contact resistance and internal resistance, and contact resistance, including indirect contact welding resistance and motor and weldment contact resistance. Welding area resistance shown in Figure 3.

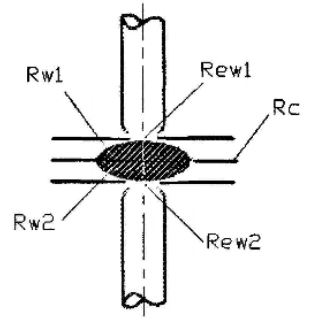

Figure 3. Spot welding resistance

This saves the need to plan the path traveled by the body welding robot when welding. We all know that the straight line between two points is the shortest, so follow this principle when working 
on bodywork robots. So at this moment, the rescue needs to optimize the working path planning of the body welding robot and try hard to find the most suitable path to improve work efficiency. And body welding robot at work, the need for welding there are many points, there may be hundreds of times in a part of the welding, then calculate the amount of data required by the robot is too large, it will increase the calculation difficulty. In this case, the robot welding path can be optimized by grouping the robots, which means that the problem of path optimization can be transformed into a traveling salesman problem.

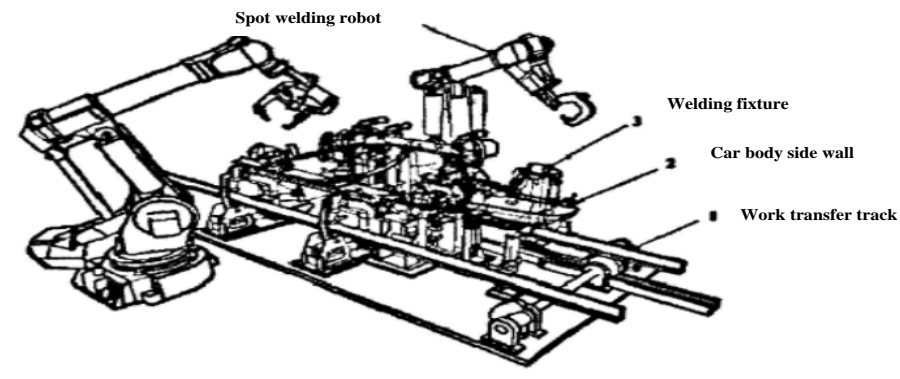

Figure 4. White body side wall station

\subsection{Choice of path optimization methods}

There are many kinds of solutions to the traveling salesman's problems, and each solution has its own characteristics. To know which method to use to solve the traveling salesman problem, we need to start with the optimization of the path planning of the welding robot. First of all, body welding robots are grouped together at work, so that the amount of bodywork to be welded is greatly reduced. Secondly, the body welding robot is mainly engaged in continuous large-scale work, so some of the accuracy requirements are not high. Some external factors do not affect the normal operation of the body welding robot. The next step is to take a certain mathematical algorithm when optimizing the robot path planning. The rational use of mathematical algorithms to solve the problem is the main consideration of the welding robot in path optimization. Body welding robots work mainly for business services, business use of robots for welding requires the use of steps and methods of use should be clear at a glance, easy to operate. So this requires that the body-robot choose a simple algorithm to optimize as much as possible in the path optimization. Based on the above considerations, heuristic method was finally chosen to optimize the path of robot welding robot. The heuristic method has the following advantages: First, the practical application is relatively strong. The heuristic method has a simple calculation process and is easy to calculate, which means that it is convenient for personnel to optimize the calculation and can save a lot of computing costs. Second, path planning can be optimized and takes less time and fewer tasks than other steps. This can save a lot of time and improve the efficiency of path optimization. Thirdly, this path optimization method can combine qualitative analysis with quantitative analysis, which greatly facilitates the calculation process.

\subsection{Body welding robot path planning optimization and implementation}

As mentioned above in the scheme selection, it is necessary to adopt a heuristic method for optimization of path planning. This algorithm is mainly taken to save the algorithm to solve the problem. This algorithm is concise and convenient, very easy to understand and calculate. The main idea of the algorithm is as follows: Firstly, to determine a point, then connect each welding point with a fixed point, then there is only one point in the route, and then calculate the total cost. Next you need to calculate the cost of connecting points a and b to a route, which is denoted as $s$ (a, b). Some conclusions can be drawn through the calculation. The larger the value of $\mathrm{s}(\mathrm{a}, \mathrm{b})$, the smaller the distance traveled by the weld when welding, that is, the path is the optimal path. According to this idea, s (a, b) can be calculated, and then find the maximum value, the maximum value is the optimization of the program we choose. When choosing the optimal path, you can take a list to choose the optimal path. First of all, you can list each program in a table, and then select the largest $\mathrm{a}, \mathrm{b}$. After the completion of the choice of a, b to test, test whether it is in the set route. 
If you can do the next calculations work, if you do not need to draw the element, in the other calculations. After the actual optimization of the path of the welding robot, it is necessary to consider the actual process and result to further optimize and optimize the path optimization, in order to make the optimal use of the optimization program to the greatest extent possible.

\section{Body welding robot path optimization specific use}

In the use of body welding robot path optimization program, we must first improve the welding robot work software. In the preparation of path optimized software, you can use C++ to write software programs. Write the main steps of the process are as follows; first, enter the solder joint, the solder joint input in the form of coordinates. Second, calculate; calculate the distance between the solder joints and welding time and other factors. Third, use the formula for further calculations. Fourth, the test process, the process to be used to test the loop body, so that a round of data screening, and finally come to the right data. The final step is to further refine the optimal path and then to arrive at the final desired optimal path. At this time the optimal path selection software implementation process. This process using $\mathrm{C}++$ to program is very simple, and the input process is also clear at a glance. This approach has great advantages for the practical application of the enterprise and can largely realize the software design of path optimization.

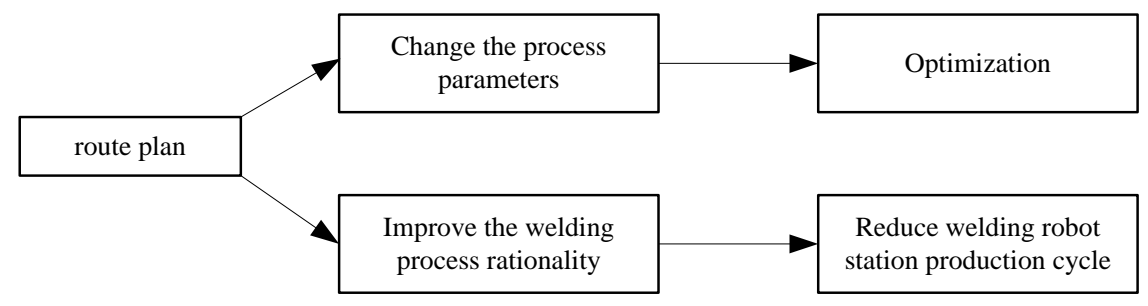

Figure 5. Path planning path

After the actual use of the optimized path, allowing the body welding work easier and easier. Car body welding work is relatively large, the calculation process is relatively complicated. However, after the path optimization, the program effectively saves the calculation time, also improves the welding work efficiency. After route optimization, the welding sequence of the welding spot is more regular, and the welding process follows the law to carry out a series of welding work. This allows the original complex and complicated welding work has become a regular follow-up, more in line with the requirements of the actual operation. And this path optimization program also solves the previous body welding robot interaction problems. By optimizing the path, each robot can "work its own way" at work, eliminating the need for interference. The benefits brought about by this are also an improvement on the efficiency of work, which is also the work advantage brought by the path optimization.

\section{Conclusions}

In this paper, we mainly optimize the robot welding path through traveling salesman's problem, and use the heuristic method to solve this path optimization problem. After optimizing the path of the body welding robot, the working efficiency of the body welding robot is greatly improved. At the same time, this optimization uses the method of computer calculation, abandoning the inefficient calculation method that used manual calculation in the past. The path optimization also greatly improves the computational efficiency, and the collar path optimization problem is more simple and reasonable. Body welding robot work is an important work process in the car manufacturing process; more optimized path can effectively improve the bodywork welding efficiency. And the path optimization can also save a lot of manpower and material resources such costs. Thus, it is very important to optimize the path planning of body welding robots. On the robot welding path optimization problem also needs more professionals to conduct a large number of research and analysis, I believe that with everyone's efforts, the future optimization of vehicle body 
welding robot path planning will be more people to put forward more reasonable optimization suggestions.

\section{Acknowledgment}

This work was supported by the Nanchang Institute of Science and Technology research project for Jiangxi Engineering Laboratory of Digital Manufacturing for Automobile Parts under Grant No. SZZX-17-15.

\section{References}

[1] HYUN S S, YOON G S. Stability and four-posture control for nonholonomic mobile robots [J]. Robotics and Automation, IEEE Transactions on, 2004.1.

Wang Tao, Yang Ruqing, Xiang Xiangming, Zhang Zhiwei. Attitude setting of articulated wheeled mobile robot with autonomous obstacle [J]. Journal of Shanghai Jiaotong University, 2001.1.

[3] Wang Yiqun, Kong Xiangdong. Control Engineering Foundation [M]. Beijing: Mechanical Industry Press, 2001.

[4] He You, Wang Guohong, Lu Dalai, Peng Yingning. Multisensor information fusion and application [M]. Electronics Industry Press, 2000. 